\title{
RESEARCH
}

\section{Portfolio Optimization: Some Aspects of Modeling and Computing}

\author{
Nguyen Hai Thanh", Nguyen Van Dinh \\ VNU International School, Building G7-G8, 144 Xuan Thuy, Cau Giay, Hanoi, Vietnam
}

Received 20 April 2017

Revised 10 June 2017, Accepted 28 June 2017

\begin{abstract}
The paper focuses on computational aspects of portfolio optimization (PO) problems. The objectives of such problems may include: expectedreturn, standard deviation and variation coefficient of the portfolioreturn rate. PO problems can be formulated as mathematical programming problems in crisp, stochastic or fuzzy environments. To compute optimal solutions of such single- and multi-objective programming problems, the paper proposes the use of a computational optimization method such as RST2ANU method, which can be applied for nonconvex programming problems. Especially, an updated version of the interactive fuzzy utility method, named UIFUM, is proposed to deal with portfolio multi-objective optimization problems.
\end{abstract}

Keywords: Portfolio optimization, mathematical programming, single-objective optimization, multi-objective optimization, computational optimization methods.

\section{Introduction}

Modern portfolio theory, fathered by Harry Markowitz in the 1950s, assumes that an investor wants to maximize a portfolio's expected return contingent on any given amount of risk, with risk measured by the standard deviation of the portfolio's return rate. For portfolios that meet this criterion, known as efficient portfolios, achieving a higher expected return requires taking on more risk, so investors are faced with a trade-off between risk and expected return. Modern portfolio theory helps investors control the amount of risk and return they can expect in a portfolio of investments such as stocks and shows that certain weighted

\footnotetext{
${ }^{*}$ Corresponding author. Tel.: 84-987221156.

Email: nhthanh.ishn@isvnu.vn

https://doi.org/10.25073/2588-1116/vnupam.4090
}

combinations of investments offer both lower expected risk and higher expected return than other combinations. Modern portfolio theory also shows that certain combinations only offer increased reward with increased risk. This set of combinations is referred to as the efficient frontier [1].

In this paper, the classical PO problem is considered: There are $\mathrm{k}$ assets (stocks)for possible investment. For each asset $i$ with return rate $\mathrm{R}_{\mathrm{i}}, \mathrm{i}=1,2, \ldots, \mathrm{k}$, expected return $\mu_{\mathrm{i}}=\mathrm{E}\left(\mathrm{R}_{\mathrm{i}}\right)$ and standard deviation $\sigma_{i}=\sqrt{V\left(R_{i}\right)}$ can be calculated based on the past data. Also the variance - covariance matrixfor the assets can be obtained. The PO problem is to choose the weights $\mathrm{w}_{1}, \mathrm{w}_{2}, \ldots, \mathrm{w}_{\mathrm{k}}$ of investments into the assets in order to optimize some objectives subject to certain constraints (see $[2,3]$ ).

For the PO problem we need the notations: 
$\mathrm{w}=\left(\mathrm{w}_{1}, \mathrm{w}_{2}, \ldots, \mathrm{w}_{\mathrm{k}}\right)^{\mathrm{T}}$,

$\mu=\left(\mu_{1}, \mu_{2}, \ldots, \mu_{k}\right)^{\mathrm{T}}$,

and the variance - covariance matrix:

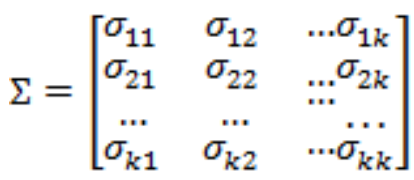

The following objectives may be considered:

io) Maximize Portfolio Expected Return: $\operatorname{Max} \mu_{P}=E\left(R_{P}\right)=w^{T} \mu$;

iio) Minimize Portfolio Standard Deviation: Min $\sigma_{\mathrm{P}}=\sqrt{V\left(R_{p}\right)}=\left(\mathrm{w}^{\mathrm{T}} \Sigma \mathrm{w}\right)^{1 / 2}$;

iiio) MinimizePortfolio Variation Coefficient $\operatorname{Min} \mathrm{VC}_{\mathrm{P}}=\sigma_{\mathrm{P}} / \mu_{\mathrm{P}}$ or $\operatorname{Max}\left(\mathrm{VC}_{\mathrm{P}}\right)^{-1}=$ $\mu_{\mathrm{P}} / \sigma_{\mathrm{P}}$

The constraints may be specified as follows

ic) $\mathrm{w}_{1}+\mathrm{w}_{2}+\ldots+\mathrm{w}_{\mathrm{k}}=1$;

iic) $\mu_{\mathrm{P}} \geq \alpha$, where $\alpha$ usually is set as $\operatorname{Max}\left\{\mu_{\mathrm{i}}\right\}$;

iiic) $\sigma_{\mathrm{P}} \leq \beta$, where $\beta$ usually is set as Min $\left\{\sigma_{\mathrm{i}}\right\}$

ivc) $\mu_{\mathrm{P}} / \sigma_{\mathrm{P}} \geq \gamma$.

It should be noted that the first constraint is the "must" requirement and, for the sake of simplicity, all the weights are proposed to be non-negative. The other constraints are optional ones that may be included in the problem formulation depending on circumstances. Moreover, other additional objectives and/or constraints may also be considered if required.

If we choose to optimize only one objective out of the three as shown above, then we have $a$ single-objective optimization problem. The $1^{\text {st }}$ objective function is a linear function, the $2^{\text {nd }}$ objective is a quadratic function, and the $3^{\text {rd }}$ objective is a fraction function of a linear expression over a quadratic expression. The $2^{\text {nd }}$ objective and the $3^{\text {rd }}$ objective are not always guaranteed to be convex / concave functions. If we choose to optimize at least two of the three objectives (or some other additional objectives), then we have a multi-objective optimization problems. In the traditional, classical setting, when all the coefficients of the programing problem are real numbers, the PO problem is to be solved in the crisp environment (see [4-6]).

The $1^{\text {st }}$ objective may be formulated as a stochastic function with return rates being treated as random variables which are assumed to follow normal distributions. In this modeling setting, the $2^{\text {nd }}$ constraint and the $3^{\text {rd }}$ constraint should be changed appropriately, and the programming problem thus obtained is to be solved in the stochastic environment (see [4-6]).

We also can apply the fuzzy programming to model the objectives and the constraintsof the PO problem as the fuzzy goals and flexible constraints. In other cases, one can use the fuzzy utility objectives to deal with the multiobjective nature of the problem. In all these cases the resulting programming problemis to be solved in the fuzzy environment (see [4-6]).

To get numerical solutions of the PO problem, appropriate commercial computing software packages or scientific computing software packages can be chosen.

In the next section of the paper, section 2, some mathematical programming models of the PO problem will be reviewed. Then, in section 3 , a single-objective optimization model of the PO problem will be considered and solved in the crisp environment. In section 4, some aspects of computing optima of the multiobjective optimization model of the PO problem will be discussed, especially an updated version of the interactive fuzzy utility method will be considered for the purpose. Finally, concluding observations will be made in section 5 .

\section{Some mathematical programming models of the $\mathrm{PO}$ problem}

It is well known, that the return rate $R_{i}$ from the investment into asset $\mathrm{i}(\mathrm{i}=1,2, \ldots, \mathrm{k})$ can be, in most cases, treated as a random variable which is proposed to follow normal distribution $\mathrm{N}\left(\mu_{\mathrm{i}}, \sigma_{\mathrm{i}}\right)$. These random variables are statistically related and this relation is expressed by the variance-covariance matrix $\Sigma$ as stated in section 1 . 
Now, the mathematical programming model for the PO problem may be set as a stochastic programming problem:

\section{Problem 1:}

$\operatorname{Max} \mathrm{R}_{\mathrm{P}}=\mathrm{R}_{1} \mathrm{w}_{1}+\mathrm{R}_{2} \mathrm{~W}_{2}+\ldots+\mathrm{R}_{\mathrm{k}} \mathrm{W}_{\mathrm{k}}$

$=\mathrm{N}\left(\mu_{1}, \sigma_{1}\right) \mathrm{w}_{1}+\mathrm{N}\left(\mu_{2}, \sigma_{2}\right) \mathrm{w}_{2}+\ldots+\mathrm{N}\left(\mu_{\mathrm{k}}\right.$, $\left.\sigma_{\mathrm{k}}\right) \mathrm{w}_{\mathrm{k}}$

$$
\begin{aligned}
& \operatorname{Min} \quad \sigma_{\mathrm{P}}=\left(\mathrm{w}^{\mathrm{T}} \Sigma \mathrm{w}\right)^{1 / 2}= \\
& \sqrt{\sum_{i=1}^{k} \sum_{j=1}^{k} \sigma_{i j} w_{i} w_{j}} \text {; }
\end{aligned}
$$

$\operatorname{Max}\left(\mathrm{VC}_{\mathrm{P}}\right)^{-1}=\mu_{\mathrm{P}} / \sigma_{\mathrm{P}}$;

subject to:

$\mathrm{w}_{1}+\mathrm{w}_{2}+\ldots+\mathrm{w}_{\mathrm{k}}=1$

$\mathrm{w}_{1}, \mathrm{w}_{2}, \ldots, \mathrm{w}_{\mathrm{k}} \geq 0$.

This problem has three objectives and the $1^{\text {st }}$ objective is the "must" requirement.

Problem 1 can be turned into a singleobjective optimization problem in crisp environment as either of the following cases.

Problem 2a:

$\operatorname{Max} \mu_{\mathrm{P}}=\mathrm{E}\left(\mathrm{R}_{\mathrm{P}}\right)=\mathrm{w}^{\mathrm{T}} \mu$

subject to:

$\mathrm{w}_{1}+\mathrm{w}_{2}+\ldots+\mathrm{w}_{\mathrm{k}}=1$

$\sigma_{\mathrm{P}} \leq \beta$;

$\mathrm{w}_{1}, \mathrm{w}_{2}, \ldots, \mathrm{w}_{\mathrm{k}} \geq 0$.

Problem 2b:

Min $\sigma_{\mathrm{P}}=\left(\mathrm{w}^{\mathrm{T}} \Sigma \mathrm{w}\right)^{1 / 2}$

subject to:

$\mathrm{w}_{1}+\mathrm{w}_{2}+\ldots+\mathrm{w}_{\mathrm{k}}=1$

$\mu_{\mathrm{P}} \geq \alpha$

$\mathrm{w}_{1}, \mathrm{w}_{2}, \ldots, \mathrm{w}_{\mathrm{k}} \geq 0$.

Problem 2c:

$\operatorname{Max}\left(\mathrm{VC}_{\mathrm{P}}\right)^{-1}=\mu_{\mathrm{P}} / \sigma_{\mathrm{P}}$

subject to:

$\mathrm{w}_{1}+\mathrm{w}_{2}+\ldots+\mathrm{w}_{\mathrm{k}}=1$

$\mathrm{w}_{1}, \mathrm{w}_{2}, \ldots, \mathrm{w}_{\mathrm{k}} \geq 0$.

Problem 1 can also be turned into the following three-objective optimization problem wherein the objectives are treated as fuzzy utility objectives in the fuzzy environment.

Problem 3:

$\operatorname{Max} \mu_{\mathrm{P}}=\mathrm{E}\left(\mathrm{R}_{\mathrm{P}}\right)=\mathrm{w}^{\mathrm{T}} \mu$;

$\operatorname{Min} \sigma_{\mathrm{P}}=\left(\mathrm{w}^{\mathrm{T}} \Sigma \mathrm{w}\right)^{1 / 2}$

$\operatorname{Max}\left(\mathrm{VC}_{\mathrm{P}}\right)^{-1}=\mu_{\mathrm{P}} / \sigma_{\mathrm{P}}$;

subject to:

$\mathrm{w}_{1}+\mathrm{w}_{2}+\ldots+\mathrm{w}_{\mathrm{k}}=1$ $\mathrm{w}_{1}, \mathrm{w}_{2}, \ldots, \mathrm{w}_{\mathrm{k}} \geq 0$.

If in the problem 1 we treat the $1^{\text {st }}$ objective as stochastic objective and other objectives as level constraints, then we have a singleobjective optimization problem which is to be solved in the stochastic environment.

Problem 4:

$\operatorname{Max} \mathrm{R}_{\mathrm{P}}=\mathrm{N}\left(\mu_{1}, \sigma_{1}\right) \mathrm{w}_{1}+\mathrm{N}\left(\mu_{2}, \sigma_{2}\right) \mathrm{w}_{2}+\ldots+$ $\mathrm{N}\left(\mu_{\mathrm{k}}, \sigma_{\mathrm{k}}\right) \mathrm{w}_{\mathrm{k}}$;

subject to:

$\mathrm{w}_{1}+\mathrm{w}_{2}+\ldots+\mathrm{w}_{\mathrm{k}}=1$

$\sigma_{\mathrm{P}} \leq \beta$

$\mu_{\mathrm{P}} / \sigma_{\mathrm{P}} \geq \gamma$

$\mathrm{w}_{1}, \mathrm{w}_{2}, \ldots, \mathrm{w}_{\mathrm{k}} \geq 0$.

Finally, problem 1 can be re-formulated as a two-objective optimization problem which is to be solved in the mixed fuzzy-stochastic environment.

Problem 5:

$\operatorname{Max} \mathrm{R}_{\mathrm{P}}=\mathrm{N}\left(\mu_{1}, \sigma_{1}\right) \mathrm{w}_{1}+\mathrm{N}\left(\mu_{2}, \sigma_{2}\right) \mathrm{w}_{2}+\ldots+$ $\mathrm{N}\left(\mu_{\mathrm{k}}, \sigma_{\mathrm{k}}\right) \mathrm{w}_{\mathrm{k}}$

Min $\sigma_{\mathrm{P}}=\left(\mathrm{w}^{\mathrm{T}} \Sigma \mathrm{w}\right)^{1 / 2}$

subject to:

$\mathrm{w}_{1}+\mathrm{w}_{2}+\ldots+\mathrm{w}_{\mathrm{k}}=1$

$\mu_{\mathrm{P}} / \sigma_{\mathrm{P}} \geq \gamma$

$\mathrm{w}_{1}, \mathrm{w}_{2}, \ldots, \mathrm{w}_{\mathrm{k}} \geq 0$.

In this problem, the $1^{\text {st }}$ objective can be treated as stochastic objective, the $2^{\text {nd }}$ objective as a fuzzy goal.

It should be mentioned here that in the literature on computing optima for the PO problem much attention is focused on the single-objective optimization models and very less attention is paid to the multi-objective optimization models in the fuzzy environment and stochastic environment (see [2, 3]).

\section{Computing the optimal solutions for the single-objective optimization model of the PO problem}

The problems $2 \mathrm{a}, 2 \mathrm{~b}$ and $2 \mathrm{c}$ as stated in section 2 are all single-objective optimization problems. These optimization problems are all non-linear programming problems since they 
contain at least one non-linear function either in the objective or in the constraints, where there is the expression:

$$
\begin{aligned}
& \operatorname{Min} \sigma_{\mathrm{P}}=\left(\mathrm{w}^{\mathrm{T}} \sum \mathrm{w}\right)^{1 / 2}= \\
& \sqrt{\sum_{i=1}^{k} \sum_{j=1}^{k} \sigma_{i j} w_{i} w_{j}}= \\
& \sqrt{\sum_{i=1}^{k} \sigma_{i i} w_{i}^{2}+\sum_{i=1}^{k} \sum_{j=1, j \neq i}^{k} \sigma_{i j} w_{i} w_{j}}
\end{aligned}
$$

Moreover, in most situations the variancecovariance matrix is not a positive definite one, and the realistic problemsneed not to be of convex, concave or d.c. programming type (see $[2,3])$. Therefore, most deterministic computational optimization methods can not guarantee to provide global optima but only local optima. Hence, in this paper we propose to use acomputational optimization method called RST2ANU method (see [5-7]) to compute the optima of $P O$ problems $2 \mathrm{a}, 2 \mathrm{~b}$ and $2 \mathrm{c}$.

Illustrative example: There are 08 stocks with the return rates $R_{i}$ as given in the following table:

\begin{tabular}{lll}
\hline $\mathrm{R}_{\mathrm{i}}$ & $\mu_{\mathrm{i}}$ & $\sigma_{\mathrm{i}}$ \\
\hline $\mathrm{R}_{1}$ & $-0.033 \%$ & $5.465 \%$ \\
$\mathrm{R}_{2}$ & $0.235 \%$ & $6.544 \%$ \\
$\mathrm{R}_{3}$ & $0.228 \%$ & $7.204 \%$ \\
$\mathrm{R}_{4}$ & $-0.439 \%$ & $6.946 \%$ \\
$\mathrm{R}_{5}$ & $0.124 \%$ & $8.707 \%$ \\
$\mathrm{R}_{6}$ & $0.818 \%$ & $4.594 \%$ \\
$\mathrm{R}_{7}$ & $0.539 \%$ & $2.858 \%$ \\
$\mathrm{R}_{8}$ & $1.462 \%$ & $6.016 \%$ \\
\hline
\end{tabular}

For the return rates, the variancecovariance matrix $\Sigma=\left[\sigma_{\mathrm{ij}}\right] \quad 8 \times 8$, whose elements are calculated based on the past data, can also be provided:

\begin{tabular}{cccccccc}
\hline 0.002987 & 0.003433 & 0.003759 & 0.003552 & 0.004195 & -0.000069 & 0.000566 & 0.0003 \\
0.003433 & 0.004282 & 0.004645 & 0.004051 & 0.005018 & -0.000098 & 0.000624 & 0.000498 \\
0.003759 & 0.004645 & 0.000519 & 0.004387 & 0.005371 & -0.000104 & 0.000662 & 0.000352 \\
0.003552 & 0.004051 & 0.004387 & 0.004824 & 0.005585 & -0.000057 & 0.000899 & 0.000767 \\
0.004195 & 0.005018 & 0.005371 & 0.005585 & 0.007582 & -0.000108 & 0.000921 & 0.001528 \\
-0.000069 & -0.000098 & -0.000104 & -0.000057 & -0.000108 & 0.002111 & 0.000516 & 0.000425 \\
0.000566 & 0.000624 & 0.000662 & 0.000899 & 0.000921 & 0.000516 & 0.000817 & 0.000291 \\
0.000345 & 0.000498 & 0.000352 & 0.000767 & 0.001528 & 0.000425 & 0.000291 & 0.003619 \\
\hline
\end{tabular}

The problem 2 a now becomes:

$\operatorname{Max} \mu_{\mathrm{P}}=$

$-0.033 \% \mathrm{w}_{1}+0.235 \% \mathrm{w}_{2}+0.228 \% \mathrm{w}_{3}-$

$0.439 \mathrm{w}_{4}+0.124 \mathrm{w}_{5}+0.818 \mathrm{w}_{6}+0.539 \mathrm{w}_{7}$

$+1.462 \% \mathrm{w}_{8}$

subject to:

$\mathrm{w}_{1}+\mathrm{w}_{2}+\ldots+\mathrm{w}_{8}=1$;

$\sigma_{\mathrm{P}}=\left(0.002987 w_{1}^{2}+0.004282 w_{2}^{2}+\right.$

$0.000519 w_{3}^{2}+0.004824 w_{4}^{2}$

$+0.007582 w_{5}^{2}+0.002111 w_{6}^{2}+$

$0.000817 w_{7}^{2}+0.003619 w_{8}^{2}$

$+0.006866 \mathrm{w}_{1} \mathrm{w}_{2}+\quad 0.007518 \mathrm{w}_{1} \mathrm{w}_{3}+$

$0.007104 \mathrm{w}_{1} \mathrm{w}_{4}+0.00839 \mathrm{w}_{1} \mathrm{w}_{5}$

$-0.000138 \mathrm{w}_{1} \mathrm{w}_{6}+0.001132 \mathrm{w}_{1} \mathrm{w}_{7}+$

$0.00069 \mathrm{w}_{1} \mathrm{w}_{8}+0.00929 \mathrm{w}_{2} \mathrm{w}_{3}$

$+0.008102 \mathrm{w}_{2} \mathrm{w}_{4}+0.010036 \mathrm{w}_{2} \mathrm{w}_{5}-$

$0.000196 \mathrm{w}_{2} \mathrm{w}_{6}+0.001284 \mathrm{w}_{2} \mathrm{w}_{7}$
$+0.000996 \mathrm{w}_{2} \mathrm{w}_{8}+0.008774 \mathrm{w}_{3} \mathrm{w}_{4}+$ $0.010742 \mathrm{w}_{3} \mathrm{w}_{5}-0.000208 \mathrm{w}_{3} \mathrm{w}_{6}$

$+0.001324 \mathrm{w}_{3} \mathrm{w}_{7}+0.000704 \mathrm{w}_{3} \mathrm{w}_{8}+$ $0.01117 \mathrm{w}_{4} \mathrm{w}_{5}-0.000114 \mathrm{w}_{4} \mathrm{w}_{6}$

$+0.001798 \mathrm{w}_{4} \mathrm{w}_{7}+0.001534 \mathrm{w}_{4} \mathrm{~W}_{8}-$ $0.00216 \mathrm{w}_{5} \mathrm{w}_{6}+0.001842 \mathrm{w}_{5} \mathrm{w}_{7}$

$+0.003056 \mathrm{w}_{5} \mathrm{w}_{8}+0.001032 \mathrm{w}_{6} \mathrm{w}_{7}+$ $\left.0.00085 \mathrm{w}_{6} \mathrm{w}_{8}+0.000582 \mathrm{w}_{7} \mathrm{w}_{8}\right)^{1 / 2}$

$\leq 2.8585 \%$;

$\mathrm{w}_{1}, \mathrm{w}_{2}, \ldots, \mathrm{w}_{8} \geq 0$.

The use of the RST2ANU computational software package (which was designed based on the RST2ANU method) with the initial guess point $\mathrm{W}=(0,0,0,0,0,0,1,0)$ provides the following numerical solutions:

$\mathrm{W}=(0.000012, \quad 0.000035,0.000000$, $0.000000, \quad 0.000010, \quad 0.193295, \quad 0.533904$, $0.272745)^{\mathrm{T}}$, 
$\mathrm{W}=\left(\begin{array}{lll}0.000012, & 0.000035,0.000000,\end{array}\right.$ $0.000000, \quad 0.000010, \quad 0.193295, \quad 0.533904$, $0.272745)^{\mathrm{T}}$,

$\mathrm{w}=(0.000002,0.000034,0.000036$, $0.000001, \quad 0.000001,0.193085,0.534023$, $0.272819)^{\mathrm{T}}$,

$\mathrm{w}=(0.000000, \quad 0.000000, \quad 0.000016$, $0.000000, \quad 0.000000, \quad 0.193239, \quad 0.533987$, $0.272757)^{\mathrm{T}}$.

All these weight vectors give the same optimal value of the largest expected return rate of the portfolio: $\mu_{\mathrm{P}}=0.008447=0.8447 \%$.

The answer to the problem $2 \mathrm{a}$ can be written as:

$\mathrm{w}^{2 \mathrm{a}}=(0 \%, 0 \%, 0 \%, 0 \%, 0 \%, 19.33 \%$, $53.40 \%, 27.27 \%$ ), i.e. $\mathrm{w}_{1}=\mathrm{w}_{2}=\mathrm{w}_{3}=\mathrm{w}_{4}=\mathrm{w}_{5}=$ $0 \%, \mathrm{w}_{6}=19.33 \%, \mathrm{w}_{7}=53.40 \%$ and $\mathrm{w}_{8}=$ $27.27 \%$.

With the data as provided in this illustrative example, the problem $2 b$ (where the lower threshold $\alpha$ for $\mu_{\mathrm{P}}$ is set to be 1.46\%) and the problem $2 c$ have the following numerical solutions (as provided by employing the RST2ANU computational software package):

$\mathrm{w}^{2 \mathrm{~b}}=(0.000000, \quad 0.000000,0.000000$, $0.000000, \quad 0.000000, \quad 0.000000, \quad 0.000000$, $1.000000)=(0 \%, 0 \%, 0 \%, 0 \%, 0 \%, 0 \%, 0 \%$, $100 \%)$ providing the lowest standard deviation of the portfolio return rate: $\sigma_{\mathrm{P}}=6.0158 \%$;

$\mathrm{w}^{2 \mathrm{c}}=(0.000000,0.000000,0.000000$, $0.000000, \quad 0.000000, \quad 0.229138, \quad 0.411787$, $0.359075)=(0 \%, 0 \%, 0 \%, 0 \%, 0 \%, 0 \%, 0 \%, 1)$ providing the largest value of the inverse of the variation coefficient of the portfolio return rate: $\left(\mathrm{VC}_{\mathrm{P}}\right)^{-1}=0.300103$.

\section{Some aspects of computing optima of the multi-objective optimization model of the PO problem}

In this section our discussion is focused on a computational method for solving the problem 3.

Problem 3:

$\operatorname{Max} \mathrm{z}_{1}=\mu_{\mathrm{P}}=\mathrm{E}\left(\mathrm{R}_{\mathrm{P}}\right)=\mathrm{w}^{\mathrm{T}} \mu$;

Min $\mathrm{z}_{2}=\sigma_{\mathrm{P}}=\left(\mathrm{w}^{\mathrm{T}} \Sigma \mathrm{w}\right)^{1 / 2}$;

$\operatorname{Max} \mathrm{z}_{3}=\left(\mathrm{VC}_{\mathrm{P}}\right)^{-1}=\mu_{\mathrm{P}} / \sigma_{\mathrm{P}}$;

subject to:

$\mathrm{w}_{1}+\mathrm{w}_{2}+\ldots+\mathrm{w}_{\mathrm{k}}=1$

$\mathrm{w}_{1}, \mathrm{w}_{2}, \ldots, \mathrm{w}_{\mathrm{k}} \geq 0$.

We can update "the interactive fuzzy utility method" (IFUM method), which initially was proposed for solving multi-objective linear programming problems (see $[4,5])$,to solve multi-objective nonlinear programming problems. This updated version of the IFUM method is first time proposed in this paper (the updated version is named as UIFUM). In particular, the UIFUM method can be used to solve the problem 3 .

\subsection{The UIFUM algorithm}

\section{The initialization step}

i) Input data for the objectives and constraint(s);

ii) Using the RST2ANU procedure to find out the optimal solutions for each of the (three) objectives subject to the given constraints. The results are summarized in the pay-off table as follows: 


\begin{tabular}{|c|c|c|c|}
\hline \multirow{3}{*}{ Assets (stocks) } & \multicolumn{3}{|c|}{ Weight vector $\mathrm{W}=\left(\mathrm{w}_{1}, \mathrm{w}_{2}, \ldots, \mathrm{w}_{8}\right)$} \\
\hline & $\begin{array}{c}\text { Max Return } \\
\text { Rate }\end{array}$ & $\begin{array}{l}\text { Min Standard } \\
\text { Deviation }\end{array}$ & $\begin{array}{l}\text { Max the Inverse of } \\
\text { Variation Coefficient }\end{array}$ \\
\hline & $\mathrm{W}^{1}$ & $\mathrm{~W}^{2}$ & $\mathrm{~W}^{3}$ \\
\hline 1 (SPY) & 0 & 0 & 0 \\
\hline 2 (MDY) & 0 & 0 & 0 \\
\hline 3 (SLY) & 0 & 0.777333 & 0 \\
\hline 4 (EFA) & 0 & 0 & 0 \\
\hline $5(\mathrm{EFM})$ & 0 & 0 & 0 \\
\hline 6 (TLT) & 0 & 0.21838 & 0.229138 \\
\hline 7 (LQD) & 0 & 0 & 0.411787 \\
\hline $8(\mathrm{GLD})$ & 1 & 0.004287 & 0.359075 \\
\hline Sum up the weights & 1 & 1 & 1 \\
\hline$\mu_{\mathrm{P}}$ of the portfolio & 0.01462 & 0.00362134 & 0.009343557 \\
\hline$\sigma_{\mathrm{P}}$ of the portfolio & 0.06015812 & 0.01954934 & 0.031134492 \\
\hline$\left(\mathrm{VC}_{\mathrm{P}}\right)^{-1}=\mu_{\mathrm{P}} / \sigma_{\mathrm{P}}$ & 0.24302619 & 0.18524122 & 0.300103091 \\
\hline
\end{tabular}

wherein $\mathrm{W}^{1}, \mathrm{~W}^{2}$ and $\mathrm{W}^{3}$ are the optimal solutions of the (three) single-objective optimization problems, respectively.

iii) Based on the pay-off information, formulate the fuzzy utility functions for the (three) objectives:

$$
\mathrm{f}_{\mathrm{u}}\left(\mathrm{z}_{1}\right)=\frac{z_{1}-z_{1}^{\mathrm{w}}}{z_{1}^{B}-z_{1}^{\mathrm{w}}}=\frac{z_{1}-0.00362}{0.01462-0.00362}=
$$
$90.920196 z_{1}-0.329253$;

$$
\mathrm{f}_{\mathrm{u}}\left(\mathrm{z}_{2}\right)=\frac{z_{2}-z_{2}^{w}}{z_{2}^{B}-z_{2}^{w}}=\frac{z_{2}-0.06016}{0.001955-0.06016}=
$$

$-24.625213 z_{2}+1.481407$

$$
\mathrm{f}_{\mathrm{u}}\left(\mathrm{z}_{3}\right)=\frac{z_{3}-z_{3}^{w}}{z_{3}^{B}-z_{3}^{w}}=\frac{z_{3}-0.18524}{0.30010-0.18524}=
$$

$8.706110 \mathrm{z}_{3}+1.612730$.

iv) The initial set of optimal solutions of the problem 3 is $\mathrm{O}_{\mathrm{p}}=\left\{\mathrm{W}^{1}, \mathrm{~W}^{2}, \mathrm{~W}^{3}\right\}$ containing (weak Pareto) optimal solutions.

\section{Iteration steps}

Step1.

i) Specify positive values $s_{1}, s_{2}, s_{3}$ for weights of the fuzzy utility functions which are chosen by the decision maker (DM) depending on his/her subjective judgment. These weights should satisfy condition: $s_{1}+s_{2}+s_{3}=1$. For example, one may choose $\mathrm{s}_{1}=0.4, \mathrm{~s}_{2}=0.4, \mathrm{~s}_{3}=0.2$ (one can use notation $\mathrm{S}=\left(\mathrm{s}_{1}, \mathrm{~s}_{2}, \mathrm{~s}_{3}\right)=(.4, .4, .2)$.

ii) Construct the aggregation utility objective function based on the values of the weights as specified above:

$$
\begin{aligned}
& \mathrm{F}_{\mathrm{au}}=\mathrm{s}_{1} \mathrm{f}_{\mathrm{u}}\left(\mathrm{z}_{1}\right)+\mathrm{s}_{2} \mathrm{f}_{\mathrm{u}}\left(\mathrm{z}_{2}\right)+\mathrm{s}_{3} \mathrm{f}_{\mathrm{u}}\left(\mathrm{z}_{3}\right) \\
& \mathrm{F}_{\mathrm{au}}=0.4 \mathrm{f}_{\mathrm{u}}\left(\mathrm{z}_{1}\right)+0.4 \mathrm{f}_{\mathrm{u}}\left(\mathrm{z}_{2}\right)+0.2 \mathrm{f}_{\mathrm{u}}\left(\mathrm{z}_{3}\right)= \\
& 0.4\left(90.920196 z_{1}-0.329253\right) \\
& +0.4\left(-24.625213 \mathrm{z}_{2}+1.481407\right)+ \\
& 0.2\left(8.706110 \mathrm{z}_{3}-1.612730\right) \\
& \mathrm{F}_{\mathrm{au}}=36.368079 \mathrm{z}_{1}-9.850085 \mathrm{z}_{2}+ \\
& 1.7412219 z_{3}-0.188315 \text {, } \\
& \text { where } \\
& \mathrm{z}_{1}=\mu_{\mathrm{P}}=-0.033 \% \mathrm{w}_{1}+0.235 \% \mathrm{w}_{2}+ \\
& 0.228 \% \mathrm{w}_{3}-0.439 \mathrm{w}_{4}+0.124 \mathrm{w}_{5}+0.818 \mathrm{w}_{6}+ \\
& 0.539 \mathrm{w}_{7}+1.462 \% \mathrm{w}_{8} \\
& \mathrm{z}_{2}=\sigma_{\mathrm{P}}=\left(0.00297 w_{1}^{2}+0.004282 w_{2}^{2}+\right. \\
& 0.000519 w_{3}^{2}+0.004824 w_{4}^{2} \\
& +0.007582 w_{5}^{2}+0.002111 w_{6}^{2}+ \\
& 0.000817 w_{7}^{2}+0.003519 w_{8}^{2} \\
& +0.006866 \mathrm{w}_{1} \mathrm{w}_{2}+0.007518 \mathrm{w}_{1} \mathrm{w}_{3}+ \\
& 0.007104 \mathrm{w}_{1} \mathrm{w}_{4}+0.00839 \mathrm{w}_{1} \mathrm{w}_{5} \\
& \text { - } 0.000138 \mathrm{w}_{1} \mathrm{w}_{6}+0.001132 \mathrm{w}_{1} \mathrm{w}_{7}+ \\
& 0.00069 \mathrm{w}_{1} \mathrm{w}_{8}+0.00929 \mathrm{w}_{2} \mathrm{w}_{3}
\end{aligned}
$$




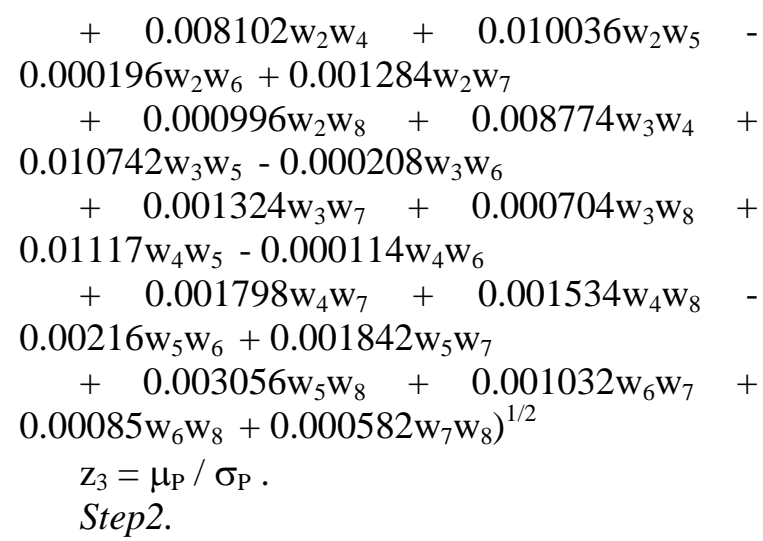

Step2.

i) Using the RST2ANU procedure to find out the optimal solution of the obtained singleobjective programming problem:

$\operatorname{Max} \mathrm{F}_{\mathrm{au}}=36.368079 \mathrm{z}_{1}-9.850085 \mathrm{z}_{2}+$ $1.7412219 z_{3}-0.188315$

subject to: $\mathrm{w}_{1}+\mathrm{w}_{2}+\ldots+\mathrm{w}_{\mathrm{k}}=1$

$\mathrm{w}_{1}, \mathrm{w}_{2}, \ldots, \mathrm{w}_{\mathrm{k}} \geq 0$.

The optimal solution is: Max $\mathrm{F}_{\mathrm{au}}=$ 0.694239 attained at $\mathrm{W}=(0,0,0,0,0,0.2345$, $0.3930,0.3724)$. With this weighting set, $\mu_{\mathrm{P}}=$ $0.009481683, \sigma_{\mathrm{P}}=0.031604131$ and $\mu_{\mathrm{P}} / \sigma_{\mathrm{P}}=$ 0.300014058 .

ii) If this optimal solution is different from those solutions in set $\mathrm{O}_{\mathrm{p}}$, the DM may include / not include it into the set $\mathrm{O}_{\mathrm{p}}$. If the DM wants to update $\mathrm{O}_{\mathrm{p}}$, he/she can go back to step 1 . Otherwise, the DM goes to

Termination.

After the termination, the set $\mathrm{O}_{\mathrm{p}}$ of optimal solutions corresponding to different weighting sets $S=\left(s_{1}, s_{2}, s_{3}\right)$ may be summarized in the following table.

\begin{tabular}{|c|c|c|c|c|c|c|}
\hline \multirow[b]{2}{*}{ Stocks } & \multicolumn{6}{|c|}{ Weight vectors $\mathrm{W}=\left(\mathrm{w}_{1}, \mathrm{w}_{2}, \ldots, \mathrm{w}_{8}\right)$} \\
\hline & $\mathrm{W}^{1}$ & $\mathrm{~W}^{2}$ & $\mathrm{~W}^{3}$ & $\begin{array}{c}\mathrm{W}^{4} \\
\mathrm{~S}=(.4, .4, .2)\end{array}$ & $\begin{array}{c}\mathrm{W}^{5} \\
\mathrm{~S}=(.5, .4, .1)\end{array}$ & $\begin{array}{c}\mathrm{W}^{6} \\
\mathrm{~S}=(.6, .3, .1)\end{array}$ \\
\hline $1(\mathrm{SPY})$ & 0 & 0 & 0 & 0 & 0 & 0 \\
\hline 2 (MDY) & 0 & 0 & 0 & 0 & 0 & 0 \\
\hline 3 (SLY) & 0 & 0.777333 & 0 & 0 & 0 & 0 \\
\hline 4 (EFA) & 0 & 0 & 0 & 0 & 0 & 0 \\
\hline 5 (EFM) & 0 & 0 & 0 & 0 & 0 & 0 \\
\hline 6 (TLT) & 0 & 0.21838 & 0.229138 & 0.234507 & 0.263026 & 0.295629 \\
\hline 7 (LQD) & 0 & 0 & 0.411787 & 0.393076 & 0.295305 & 0 \\
\hline $8(\mathrm{GLD})$ & 1 & 0.004287 & 0.359075 & 0.372417 & 0.441669 & 0.704371 \\
\hline $\begin{array}{l}\text { Sum up the } \\
\text { weights }\end{array}$ & 1 & 1 & 1 & 1 & 1 & 1 \\
\hline $\begin{array}{l}\mu_{\mathrm{P}} \text { of the } \\
\text { portfolio }\end{array}$ & 0.01462 & 0.0036213 & 0.0093435 & 0.00948168 & 0.010200447 & 0.012716149 \\
\hline $\begin{array}{l}\sigma_{\mathrm{P}} \text { of the } \\
\text { portfolio }\end{array}$ & 0.0601581 & 0.0195493 & 0.0311344 & 0.03160413 & 0.034322977 & 0.046443696 \\
\hline $\begin{array}{c}\left(\mathrm{VC}_{\mathrm{P}}\right)^{-1}= \\
\mu_{\mathrm{P}} / \sigma_{\mathrm{P}}\end{array}$ & 0.2430261 & 0.1852412 & 0.3001030 & 0.30001405 & 0.297190052 & 0.273797099 \\
\hline
\end{tabular}


Based on the information of the above table, the DM may choose the most preferred optimal solution to implement his/her investment portfolio. If desired, the DM may also use a group decision making method to make the investment decision. For example, the following investment decision seems to be quite good: Invest $26.30 \%$ of the total fund into the $6^{\text {th }}$ stock (TLT), $29.53 \%$ into $7^{\text {th }}$ stock (LQD) and $44.17 \%$ into the $8^{\text {th }}$ stock (GLD) to get a good level of $\mu_{\mathrm{P}}$ $=1.02 \%$ at a reasonable low level of risk $\sigma_{\mathrm{P}}=$ $3.43 \%$.

It is interesting to note that the optimal solutions as summarized in the above table all belong to the set of Pareto optimal solutions (also called efficient solutions). This set may be considered as the theoretical extension of the efficient frontier, which graphically represents the efficient portfolios obtained when only two first objectives out of the three are considered.

\section{Concluding observations}

This paper deals with some modeling and computing aspects of the classical PO problem. It has been shown that the PO problem can be modeled as a single- objective or a multiobjective programming problem which may be, depending on the realistic circumstances, treated in a crisp, stochastic and / or fuzzy environment. Although the illustrative example is quite a classical and simple one, it has been indicated that the PO programming problem is not a linear programming and not necessarily to be a convex or d.c. programming problem. Because of this reason, the $\mathrm{PO}$ problem is challenging all the experts in the field of mathematical programming and computational optimization to find out the global optima or the best investment decisions of the PO problem.

This paper has also shown that the RST2ANU method can be of use in computing optima for the PO single-objective as well as multi-objective programming problems. The method is in nature a stochastic optimization method. The possibility to improve the method (or any other stochastic method) is in incorporating it with a suitable deterministic optimization method to find most of local optimal solutions which may contain the global solution with a high probability. An updated version of the interactive fuzzy utility method (IFUM) has been proposed first time in this paper to find the optima of the PO multi-objective programming problem. Because of the time limitation, we could not show how to use the updated versions of multi-objective optimization methods (the reference direction interactive method, called RDIM, and the interactive satisficing method, named PRELIME $[6,8,9]$, which were developed by us, to solve the PO problem as has been formulated in section 2 (see Problem 4 and Problem 5).

Therefore, the scope for further research in modeling and computing optima of the PO problem is, first of all, to improve the efficiency of the existing computational optimization methods, including all computational techniques as mentioned in this paper as well as some others. Also, the essential matter of realistic PO problems is that the data for PO realistic problems is a kind of so called big data, which is often characterized by $3 \mathrm{Vs}$ : the extreme volume of data, the wide variety of data types and the velocity at which the data must be processed. Hence, another research direction is to combine data mining and statistical analysis with optimization tools. 


\section{References}

[1] Sabbadini, Tony, Manufacturing Portfolio Theory, International Institute for Advanced Studies in Systems Research and Cybernetics, working paper, 2010.

[2] Wai-Sum Chan and Yiu-KuenTse, Financial Mathematics for Actuaries, Updated Edition, McGraw - Hill Education, Singapore, 2013.

[3] Jaehyun Park, Ahmed Bou-Rabee and Stephen Boyd, Portfolio Optimization, EE103 Stanford University Lecture note, 2014.

[4] Nguyen Hai Thanh, Applied Mathematics (in Vietnamese), The Hanoi National University of Education's Publishing House, Hanoi, 2005.

[5] Nguyen Hai Thanh, Optimization (in Vietnamese), The Hanoi University of Science and Technology's Publishing House, Hanoi, 2006.

[6] Nguyen Hai Thanh, Optimization in FuzzyStochastic Environment and its Applications in
Industry and Economics, Internationalization Studies, 1 (2012), 131.

[7] Chander Mohan, Nguyen Hai Thanh, A Controlled Random Search Technique Incorporating the Simulated Annealing Concept for Solving Integer and Mixed Integer Global Optimization Problems, Computational Optimization and Applications, 14 (1999), 103.

[8] Chander Mohan, Nguyen Hai Thanh, Reference Direction Method for Solving Multi-objective Fuzzy Programming, European Journal of Operational Research, 107 (1998), 599.

[9] Chander Mohan, Nguyen Hai Thanh, An Interactive Satisficing Method for Solving Multiobjective Mixed Fuzzy-Stochastic Programming Problems, International Journal for Fuzzy Sets and Systems, 117 (2001), 61. 